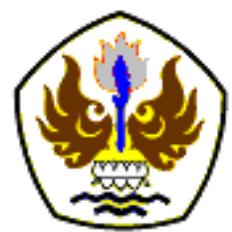

INFOMATEK

Volume 21 Nomor 2 Desember 2019

\title{
RANCANG BANGUN PEMANAS AIR (WATER HEATER) DENGAN MENGGUNAKAN BATERAI BERBASIS ARDUINO PRO MINI
}

\author{
Oleh $^{*}$, Iman Dirja, Muhamad Arif Jihan \\ Program Teknik Mesin \\ Fakultas Teknik - Universitas Singaperbangsa Karawang
}

\begin{abstract}
Abstrak: Pemanas atau sering disebut juga heater merupakan salah satu jenis pemanas yang memanfaatkan arus listrik sebagai input daya untuk menghasilkan listrik. Arus listrik yang dihasilkan kebanyakan merupakan arus bolak balik (AC) karena daya yang dibutuhkan cukup besar untuk menaikan suhu pada heater tersebut. Karena kebutuhan daya yang cukup besar maka pemakaian listrik juga akan meningkat sehingga konsumsi dan biaya akan cukup besar dikeluarkan. Penelitian ini bertujuan untuk melakukan suatu rancangan dan membuat suatu bentuk pemanas air dengan menggunakan Arduino pro mini agar menghasilkan daya yang kecil yang dimanfaatkan dalam memanaskan heater tersebut. Heater yang berbasis elektronika daya memiliki keterkaitan erat dengan frekuensi kerja. Nilai tegangan dan arus masukan, dan bentuk benda yang akan dipanaskan. Masing-masing faktor tersebut memiliki pengaruh terhadap karakteristik panas yang dihasilkan. Dengan menggunakan microcontroller dan elektronika daya, faktor-faktor tersebut dapat diubah nilainya sehingga memungkinkan untuk pengujian karakteristik panas.
\end{abstract}

Kata kunci: Pemanas Air, Microcontroller, Arduino Pro mini

\section{PENDAHULUAN}

Heater merupakan teknologi yang banyak dikembangkan karena heater tidak menggunakan api untuk memanaskan benda melainkan dengan menginduksi yang didapat dari arus listrik bolak-balik mengalir melalui koil yang terbuat dari tembaga (Mukhlis dkk. [1]). Arus listrik bolak-balik yang di dapat akan menimbulkan medan elektromagnetik yang besarnya berubah-ubah.

\footnotetext{
") olehkrw1969@gmail.com
}

Pertama diterima : 1 Agustus 2019

Direvisi : 13 Agustus 2019

Disetujui untuk publikasi: 19 September 2019
Salah satu bentuk kompor pemanas air yang kita temukan dalam kehidupan sehari-hari adalah heater induksi (Hakiki dkk. [2]). Kompor jenis ini tidak banyak digunakan di Indonesia dan belum ada produsen yang memproduksinya secara masal. Masyarakat di Indonesia masih banyak yang menggukan kompor berbahan bakar gas yang kini perlahan mulai langka ketersedian gasnya. Sebaliknya di negara maju heater ini sudah banyak digunakan, terlebih dari cara pemakaian lebih sederhana karena tidak menggunakan bahan bakar gas melainkan menggunakan listrik, heater ini menggunakan 
induksi yang terbuat dari coil tembaga yang di aliri arus listrik (Wilis dkk. [3]) dan tidak mengggunakan api sehingga mengurangi resiko terjadinya kebakaran.

Heater yang berbasis elektronika daya memiliki keterkaitan erat dengan frekuensi kerja (Noufal dkk. [4]). Nilai tegangan dan arus masukan, dan bentuk benda yang akan dipanaskan. Masing-masing faktor tersebut memiliki pengaruh terhadap karakteristik panas yang dihasilkan. Dengan menggunakan microcontroller dan elektronika daya, faktorfaktor tersebut dapat diubah nilainya sehingga memungkinkan untuk pengujian karakteristik panas (Junsupratyo dkk. [5]).

\section{METODOLOGI}

Pelaksanaan kajian ini dilakukan dengan tahapan seperti yang terlihat di Gambar 2. Tahapan dalam penelitian ini meliputi studi literatur, perancangan alat, pembuatan alat, pengujian dan analisis hasil.

Perancangan alat dibuat sesuai dengan kondisi terbaik, sedangkan pembuatan alat disempurnakan dengan dasar hasil pengujian. Kedua tahapan ini melalui beberapa pengulanan untuk mendapatkan hasil yang baik.

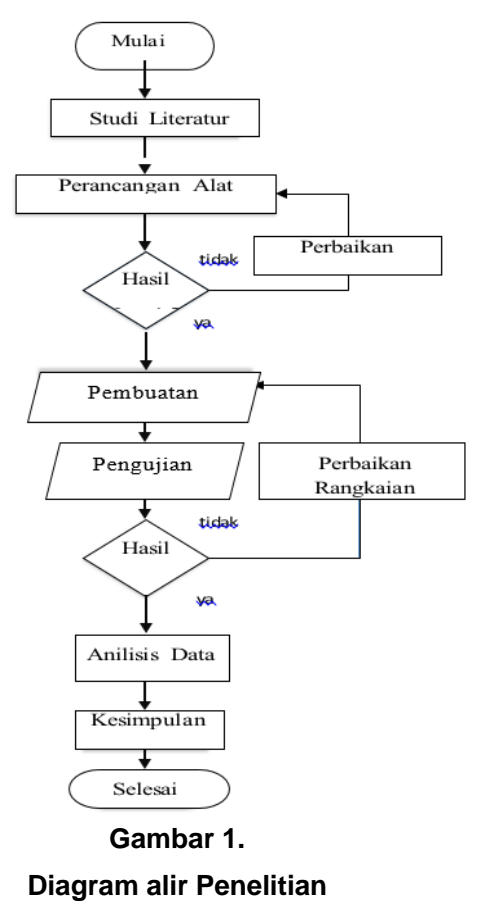

\subsection{Jenis Perancangan dan Pembuatan}

Jenis perancangan dan pembuatan adalah Experiment untuk merancang dan membuat alat heater berbasis Arduino promini. Tujuanya adalah untuk mencari nilai dari temperatur kompor dan cangkir alumunium yang dilakukan dengan pengujian berkapasitas 150 $\mathrm{ml}$ hingga $600 \mathrm{ml}$.

\subsection{Peralatan dan Bahan}

Penelitian ini membutuhkan alat dan bahan untuk mendapatkan hasil pengujian yang akan dicari nilai temperatur pada kompor dan temperatur pada gelas alumunium serta mengukur waktu titik didih yang akan di gunakan air yang berkapasitas $150 \mathrm{ml}$ hingga $600 \mathrm{ml}$. 
Rancang Bangun Pemanas Air (Water Heater) dengan menggunakan Baterai Berbasis Arduino Pro Mini

A. Alat

Gambar 2 memperlihatkan alat utama yang digunakan dalam penelitian ini, yaitu heater.

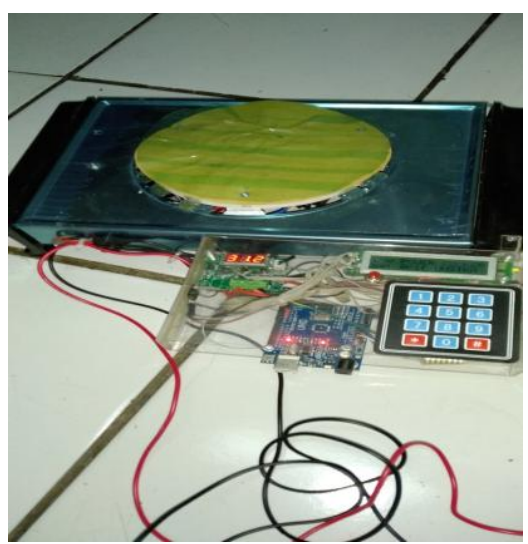

Gambar 2.

Heater

B. Bahan

1. Aki

Aki jenis basah Yuasa berkapasitas 12 $\mathrm{V}, 10 \mathrm{~A}$.

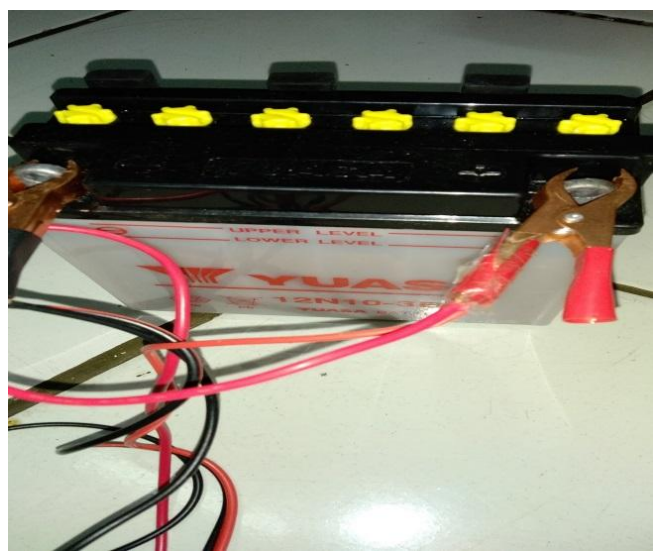

Gambar 3.

Aki

Aki digunakan sebagai sumber energi yang menghasilkan daya listrik untuk dapat membuat kumparan tembaga menjadi listrik.

\section{Charger}

Charger digunakan untuk mengisi daya listrik dan membantu kinerja dari aki.

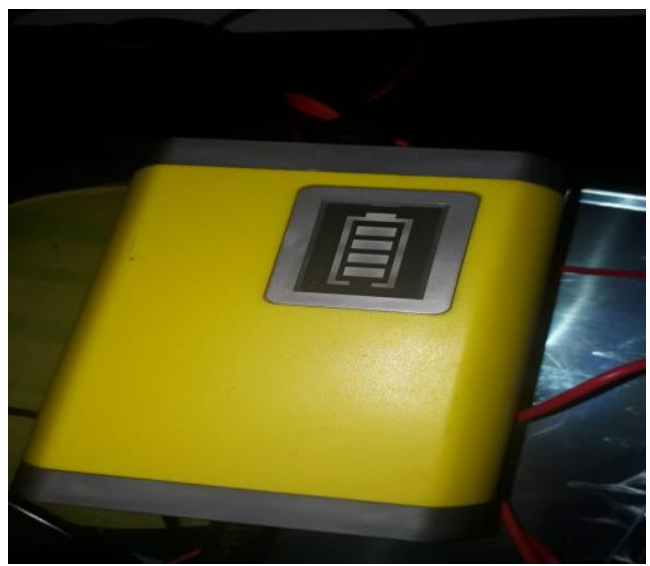

Gambar 4.

Charger

3. Termokopel

Termokopel digunakan untuk mendeteksi atau mengukur temperatur melalui dua jenis logam konduktor berbeda yang digabung pada ujungnya.

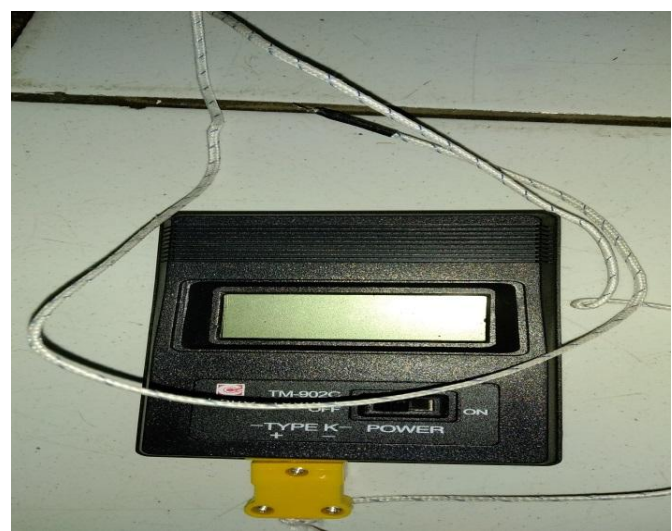

Gambar 5.

Termokopel 


\section{Stopwatch}

Stopwatch digunakan untuk mengukur waktu pada proses pemanasan hingga sampai ke titik didih air.

5. Panci alumunium

Panci aluminium ini digunakan untuk wadah air penghantar panas.

\subsection{Data Spesifikasi Alat}

Spesifikasi alat yang digunakan dalam penelitian ini adalah sebagai berikut:

$\begin{array}{ll}\text { Voltase } & : \text { DC } 12 \text { s.d } 24 \text { Volt } \\ \text { Arus } & : 6 \text { sd } 20 \text { Ampere } \\ \text { Frekuensi } & : 150 \mathrm{KHz} \\ \text { Watt } & : 100 \mathrm{sd} 1700 \mathrm{~W} \\ \text { Aki } & : 12 \text { Volt dan } 10 \text { Ampere } \\ \text { Charger } & : 13,8 \text { Volt } \\ \text { Controling } & : \text { Arduino Atmega } 328 \\ \text { Panel } & : \text { keypad } \\ \text { Monitoring } & : \text { LCD } \\ \text { Tinggi } & : 65 \mathrm{~mm} \\ \text { Lebar } & : 290 \mathrm{~mm} \\ \text { Panjang } & : 360 \mathrm{~mm} \\ \text { Berat } & : 3,4 \mathrm{~kg}\end{array}$

\section{ANALISIS DAN PEMBAHASAN}

\subsection{Perancangan Pemanas Air}

Gambar 6 memperlihatkan hasil desain layout dari rangkaian pemanas induksi.
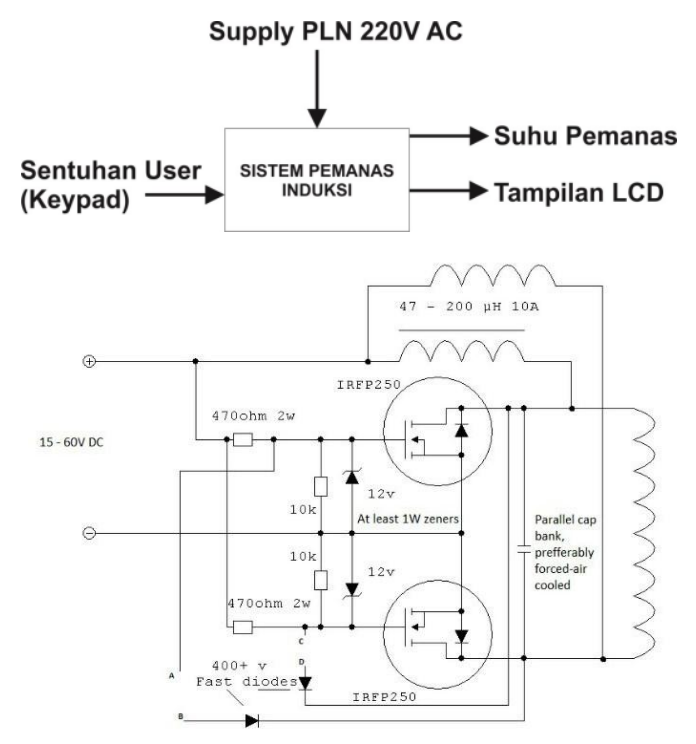

Gambar 6.

Desain Layout Rangkaian Pemanas Induksi

Tegangan yang masuk pada rangkaian akan terus masuk hingga mencapai lilitan sekunder, di lilitan sekunder ini tegangan dan arus yang masuk akan dirubah menjadi daya listrik untuk dapat memasok daya ke lilitan primer. Selain diteruskan menuju lilitan, tegangan yang masuk akan menuju MOSFET, arus dan tegangan masuk melalui percabangan pertama, sebelum masuk pada MOSFET arus akan dibatasi menggunakan resistor $470 \Omega$, selanjutnya arus yang masuk akan distabilkan menggunakan resistor $10 \mathrm{k} \Omega$. Tegangan yang masuk juga dibatasi menggunakan dioda zener agar tegangan yang masuk hanya bernilai $12 \mathrm{~V}$.

Gambar 7 memperlihatkan hasil desain rangkaian kontroler dalam simulasi. 


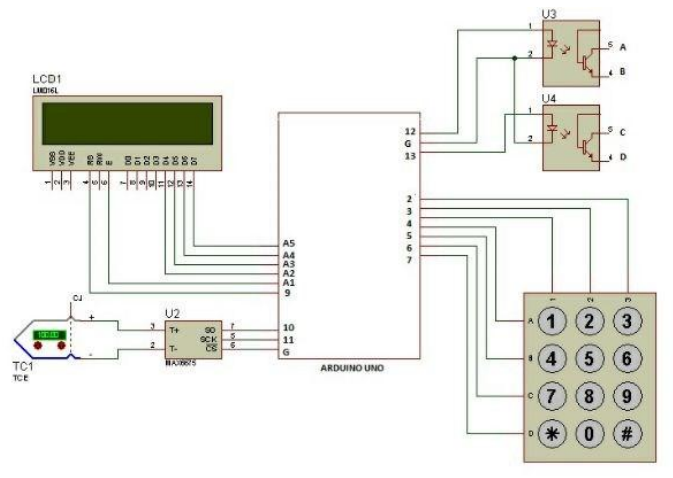

Gambar 7.

Desain Rangkaian Kontroler dalam Simulasi

Arduino akan menerima masukan dari keypad sesuai dengan tombol yang ditekan pada keypad, setelah itu Arduino akan meneruskan masukan keypad tersebut pada rangkaian Arduino Nano, pada saat meneruskan masukan ini lampu yang diletakan diantara rangkaian Arduino Uno dan Arduino Nano akan menyala, sebagai indikator adanya perpindahan inputan arus yang melaluinya selanjutnya pada rangkaian Arduino Nano perintah tadi akan masuk komponen clock. Pada Arduino Nano arus listrik di ubah frekuensinya sesuai dengan pengaturan delay, selanjutnya ketika proses perubahan ini lampu yang tersambung dengan Arduino Nano akan menyala sebagai indikator adanya arus yang masuk pada Arduino Nano, selanjutnya hasil perubahan frekuensi arus tersebut akan kembali dikirimkan kepada rangkaian Arduino Uno, untuk diteruskan pada rangkaian pemanas.

\section{KESIMPULAN}

Pemanas air yang dirancang dan dibuat merupakan jenis pemanas air dengan menggunakan microcontroller yang berfungsi untuk mengatur temperatur pemanasan. Daya yang dibutuhkan berasal dari aki yang diisi dengan menggunakan charger, sehingga kemungkinan penggunaan kalau daya habis bisa diisi kembali. Penggunaan yang relatif sederhana dan gampang sehingga efisiensi pemakaian sangat baik.

\section{DAFTAR PUSTAKA}

[1] Mukhlis, Y., Yapie, A. K. "Pemanas dengan Sistem Pendeteksi Suhu Otomatis dan Pengaman Kebocoran Panas," Jurnal IImiah Teknologi dan Rekayasa, vol. 13 no. 3, pp.186-192, 2010.

[2] Hakiki, M.F., Riandadari, D. "Rancang Bangun Sistem Induction Heater berbasis Mikrokontroler ATMEGA 328," JRM, vol. 4 no. 3, pp. 83-89, 2018.

[3] Wilis, G.R., Farid, A. "Perencanaan Tabung Heater pada Aplikasi Air Condition (AC) Double System 1 PK," Engineering, vol. 14 no. 1, pp. 1-6, 2017.

[4] Noufal, M., Kusuma, I.G.B.W. "Analisa Perpindahan Panas pada Heater Tank FASSIP-01," Jurnal METTEK Jurnal IImiah Nasional dalam Bidang IImu Teknik Mesin, vol. 3 no. 1, pp. 1-10, 2017. 
Infomatek Volume 21 Nomor 2 Desember 2019 : 91 - 96

[5] Junsupratyo, R., Sappu, F.P., Lakat, A.M.A. "Analisis Efisiensi Efektif High Pressure Heater (HPH) Tipe Vertikal UShape di Pembangkit Listrik Tenaga Uap Amurang Unit I," Jurnal Online Poros

Teknik Mesin, vol. 7 no. 1, pp. 37-45, 2018. 